\title{
Correlating the effects of flow and telepresence in virtual worlds: Enhancing our understanding of user behavior in game-based learning
}

\author{
Anthony Faiola ${ }^{a}$, Christine Newlon ${ }^{\mathrm{a}}$, Mark Pfaff ${ }^{\mathrm{a}}$, Olga Smyslova $^{\mathrm{b}}$ \\ ${ }^{a}$ Indiana University, School of Informatics (IUPUI), Indianapolis, IN, USA \\ ${ }^{\mathrm{b}}$ Kaiser Permanente, USA
}

Article history:

Available online $\mathrm{xxxx}$

\section{Keywords:}

Flow

Telepresence

Human-computer interaction

Virtual worlds

Gaming

Online learning

\begin{abstract}
A B S T R A C T
Recent research on online learning suggests that virtual worlds are becoming an important environment to observe the experience of flow. From these simulated spaces, researchers may gather a deeper understanding of cognition in the context of game-based learning. Csikszentmihalyi (1997) describes flow as a feeling of increased psychological immersion and energized focus, with outcomes that evoke disregard for external pressures and the loss of time consciousness, issuing in a sense of pleasure. Past studies suggest that flow is encountered in an array of activities and places, including those in virtual worlds. The authors' posit that flow in virtual worlds, such as Second Life (SL), can be positively associated with degrees of the cognitive phenomenon of immersion and telepresence. Flow may also contribute to a better attitude and behavior during virtual game-based learning. This study tested three hypotheses related to flow and telepresence, using SL. Findings suggest that both flow and telepresence are experienced in SL and that there is a significant correlation between them. These findings shed light on the complex interrelationships and interactions that lead to flow experience in virtual gameplay and learning, while engendering hope that learners, who experience flow, may acquire an improved attitude of learning online.
\end{abstract}

\section{Introduction}

"Flow" or "optimal experience" is a highly enjoyable state of consciousness that occurs when our skills match the challenges that we are undertaking. Csikszentmihalyi (1997) describes flow as a feeling of enjoyment and psychological immersion, energized focus, and involvement, often accompanied by positive emotions or sense of pleasure. In such a state of mind, time appears to stand still, we lose our sense of self, and we enjoy engaging in an activity for its own sake. Flow's benefits relative to other states of consciousness make it a useful goal as people look to building virtual environments for online business, health care, education, and gaming.

Salmon (2009) suggests that virtual space has created a context for the "new cultural experience"' (p. 532). Many of the activities we currently associate with the two-dimensional Web will eventually develop into the three-dimensional (3D) Web (Manyika, Roberts, \& Sprague, 1965), including 3D applications that integrate real-life with virtual "learning activities that enable unstructured spaces for interaction' ' (Savin-Baden, 2008, p. 528). Such environments already provide affordances, such as particular game styles,

Corresponding author.

E-mail addresses: faiola@iupui.edu (A. Faiola), cnewlon@iupui.edu (C. Newlon), mpfaff@iupui.edu (M. Pfaff), olga.smyslova@gmail.com (O. Smyslova). visual features, personalization, independence (ownership), and immersion that appeal to high school and college age users (Salmon, 2009). Ultimately, what the so-called "play-learner" experiences is what Warburton (2009) refers to as "experiential learning, cooperative learning, and game-based learning", (p. 421). This has major implications for the field of education.

Virtual worlds now allow educators to extend the traditional pedagogical formula for learning well beyond both brick (traditional schools) and click (traditional educational software) paradigms currently employed. In addition to individual or personal flow experiences, students may also experience social flow while using computer games that cause them to interact with one another within a virtual learning community (Inal and Cagiltay, 2007). In 3D space participants learn to play, establish group affiliations, and create a strong sense of presence. The small groups of users (represented by avatars) formed in these settings have the ability to learn a range of topics together (Salmon, 2009). By applying Csikszentmihalyi and Csikszentmihalyi's (1988) flow principles to the areas of online gameplay and learning, designers can create virtual worlds that present more opportunities for flow. Early at- tempts at applying flow theory to such ends include investigations of online consumer behavior and marketing (Hoffman \& Novak, 1996), computer-mediated communication (Trevino \& Webster, 1992), and user intrinsic interest, curiosity and attention (Webster, Trevino, \& Ryan, 1993).

This is the author's manuscript of the article published in final edited form as: Faiola, A., Newlon, C., Pfaff, M., \& Smyslova, O. (2013). Correlating the effects of flow and telepresence in virtual worlds: Enhancing our understanding of user behavior in game-based learning. Computers in Human Behavior, 29(3), 1113-1121. http://dx.doi.org/10.1016/j.chb.2012.10.003 
The studies described above suggest that flow experience is a significant cognitive state in online virtual community behavior that may influence serious gameplay and learning. In the future, online environments (and the functions and tasks they present to users) will need to facilitate flow experience. Hence, it is imperative that designers of virtual worlds understand the mechanisms underlying the enjoyment of virtual experiences and flow. This is argued by Finneran and Zhang (2003), who called for further research into flow because of its important contribution to our understanding of the optimal experience.

Telepresence is also a sensation unique to online environments, which causes users feel they are part of the action (Novak, Hoffman, \& Yung, 2000). Telepresence has been shown to support exploratory behavior in online environments such as virtual communities (Finneran \& Zhang, 2005) and may be a critical means of increasing the user's sense of "being there," i.e., being completely immersed in virtual space. For example, video gamers often become totally absorbed in the experience of a game's flow, thereby experiencing a distorted sense of time and many positive emotions. In such a mental state, telepresence transports the player to a virtual place where their connection with real time and space slowly fade into the background of consciousness, while flow takes a prominent place. Gamers consider this an optimal experience, one that is highly valued, desired, and indicative of the "flow experience." Work of several researchers who have published findings on the relationship between flow and telepresence and virtual learning and gameplay is also significant (Draper \& Blair, 1996; Finneran \& Zhang, 2003; Novak \& Hoffman, 1997; Sheridan, 1992; Steuer, 1992).

With the emergence of virtual worlds, such as Second Life (SL), calls for research into flow in the context of game-based learning have also increased. None of this research, however, focuses specifically on flow and telepresence as virtual phenomena that can enhance the learning experience while promoting exploration and creativity. Therefore, this paper first examines past research on flow phenomenon to better identify and understand telepresence in a virtual world and then examines its application and relevance to gameplay and virtual learning. Also, the purpose of the study described here is to determine the degree to which flow and telepresence are experienced in a virtual environment, such as SL, as well as the level of correlation between them. Finally, this paper examines the implications of the findings of the research, building on an earlier pilot study (Faiola \& Smyslova, 2009). From these findings, the authors argue that subjective levels of flow may be positively associated with degrees of immersion and telepresence.

\section{Implications of flow for learning}

The notion of 'flow' was introduced by Csikszentmihalyi (1975) as a technical term to describe the good feeling or "optimal experience" people have as a motivating factor in their daily activities such as work, sports, and artistic performance. Although Csikszentmihalyi's research was part of the larger field of intrinsic motivation, his investigation of flow was contrary to the traditional utility-centric motivational theories of the time (Csikszentmihalyi \& Csikszentmihalyi, 1988; Moneta \& Csikszentmihalyi, 1996). Csikszentmihalyi referred to flow as an experience people had when they "worked hard, not in order to get conventional rewards, but because the work itself was rewarding. ..." (Csikszentmihalyi and Csikszentmihalyi, 1988, p. 5). Similar to the work of Csikszentmihalyi, Maslow (1965) ascribed this motivation to the need to find one's potentiality or limitations through an activity that is intensely focused.

A number of studies by Csikszentmihalyi and Csikszentmihalyi (1988), Csikszentmihalyi $(1990,1997)$ analyze how users experi- ence flow in online information-seeking, and the correlation between user skill level and propensity to experience flow. Other researchers found that flow and high levels of enjoyment and control in computer-mediated interactions were correlated with higher online experimentation and exploration (Ghani \& Deshpande, 1994; Ghani, Supnick, \& Rooney, 1991; Katz, 1987).

Key to understanding flow is the concept of the autotelic experience. The autotelic experience is the result of an activity or situation that produces its own intrinsic motivation, rewards, or incentives, specifically without any outside goals or rewards. The autotelic experience is a common feeling among all people that experience flow when their attention is focused on a limited stimulus field. Csikszentmihalyi and Csikszentmihalyi (1988) states that in an autotelic state, people "forget personal problems, lose their sense of time and of themselves, feel competent and in control, ... have a sense of harmony and union with their surroundings... and cease to worry about whether the activity will be productive and whether it will be rewarded" (p. 182).

Flow is a complex concept that is difficult to operationalize because of a range of qualifiers. Csikszentmihalyi (1990) describes nine dimensions of flow, which include: (1) clear goals, (2) immediate feedback, (3) a match between personal skills and challenges, (4) merger of action and awareness, (5) concentration on the task, (6) sense of control, (7) loss of self-consciousness, (8) altered sense of time, and (9) the experience of becoming “'autotelic,' i.e., doing an activity for its own sake or its own intrinsic reward. A review of the literature by Rodriguez-Sanchez and Schaufeli (2008) suggests that a more condensed definition of flow as an optimal experience can be composed of three basic elements, including: absorption, enjoyment, and intrinsic interest. ${ }^{1}$ Also, in a study by Hoffman and Novak (1996) to validate correlations between flow experience and online learning, findings support the existence of five sub-constructs, including: enjoyment, telepresence, focused attention, engagement, and time distortion.

\subsection{Flow and learning in a virtual world}

The notion of intrinsic motivation has significant implications for researchers seeking to understand how learning activities and environments can engender motivation in students. This motivational phenomenon is often seen when the goals and rewards of learning are meaningful or when the learning assists the learner in obtaining valued accomplishments (Brandt, 1995; Chance, 1992). The concept of intrinsic motivation is associated directly with flow, because whatever produces flow becomes its own reward, its own intrinsic motivation.

As a balance between challenge and skill, flow occurs during the learning process as a feeling of pleasure that issues from achieving realistic goals and overcoming prescribed challenges (Csikszentmihalyi, 1990). Many researchers argue that the composition of an activity must be in the context of explicit challenges, focused goals and concentration, and control (Chan \& Ahern, 1999), and Finneran and Zhang (2005) hold that the effect of flow is increased in learning, at which time it has a direct impact on attitude and behavior. They cite several studies that indicate that flow

\footnotetext{
1 Abserption refers to the sense of involvement with total concentration or

immersion (being entirely engrossed in the activity at hand), with focused attention and loss of self-consciousness ( Csikszentmihalyi, 1997; Ghani \& Deshpande, 1994; Lutz \& Guiry, 1994; Moneta \& Csikszentmihalyi, 1996; Trevino \& Webster, 1992; Novak \& Hoffman, 1997). Enjoyment refers to the positive affect with the experience of pleasure (i.e., being intrinsically enjoyable) being directly associated with the activity at hand ( Ghani \& Deshpande, 1994; Moneta \& Csikszentmihalyi, 1996; Privette \& Bundrick, 1987; Novak \& Hoffman, 1997). " Intrinsic Interest'” refers to the interest or drive to perform an (autotelic) activity for its own sake, rather than for any other extrinsic reason or purpose (Moneta \& Csikszentmihalyi, 1996; Trevino \& Webster, 1992; Novak \& Hoffman, 1997).
} 
shows great promise in its ability to "yield increased learning, [and] improved attitudes...' (p. 98).

There is also a growing body of research examining the effect that flow has on learning. The findings of a study by Shin (2006) suggest that students in "high flow were more likely to be satisfied with the virtual course than students in low flow. ... [implying that] a positive impact of flow on student-learning achievement is highly plausible ..." (p. 717). This research on flow and virtual learning suggests that further investigation is required to identify variables which, as part of the flow experience in learning, directly influence the intentions or behaviors of users of virtual worlds (Davis, 1989).

An example of this interest has been a recent trend of research on online 3D gaming environments and virtual worlds (Carroll and Thomas, 1988; Faiola \& Voiskounsky, 2007; Pilke, 2004; Reid, 2004; Somekh, 2003; Steuer, 1992; Voiskounsky, Mitina, \& Avetisova, 2004). In part, these studies have sought to understand how to facilitate flow for users of massively multiplayer online role playing games (MMORPGs), e.g., World of Warcraft. In addition to these gaming environments, however, there are a number of nongaming environments that may also provide flow for their users. These virtual worlds are broadly classified as places for exploration and creativity, or simply $3 \mathrm{D}$ chat spaces for community interaction. The most popular virtual worlds are Active Worlds, BrandWorlds, Croquet, Kaneva, Lively, Multiverse, Smallworlds, Twinity, Worlds.com, and Second Life. Each is able to provide a virtual community life designed to be scalable and support many online users.

Three-dimensional environments like Second $\mathrm{Life}^{2}$ (SL) provide virtual spaces for exploration and creativity that enhance the learning experience. Today, there are over 300 million registered users who spend time within virtual worlds (Spence, 2008). Of all online spaces, SL represents the most developed virtual environment for social interaction (Edirisingha, Nie, Pluciennik, \& Young, 2009; SavinBaden, 2008), becoming a platform that provides increased potential for educators. Program developers should make use of the infrastructure and functionality already in place in virtual worlds to build objects and environments using graphics and audio tools that enhance users' immersive experience.

The technical infrastructure of virtual worlds generally includes tools for avatar creation and the dissemination of knowledge, e.g., blogs, wikis, and various forms of social networking. Most of these virtual communities support online interpersonal experiences and facilitate communication and learning. Providing such tools to implement diverse online experiences will provide virtual learners the necessary functionality to induce flow. In such virtual learning environments, students have the tools to go through a personal transformation that includes a temporary transfer of their realworld identity to a self-created identity known as an avatar. The avatar allows anonymity, which permits online learners a greater sense of freedom and immersion with each learning experience. Virtual worlds are uniquely qualified to provide users the ability to project themselves onto another entity. As Witmer and Singer (1998) hold, virtual worlds provide a sense of being "enveloped

\footnotetext{
${ }^{2}$ Second Life (SL) is a 3D virtual world created by Linden Labs (released in 2003), with over 16 million registered accounts (Linden Research, 2008). Users interact with existing or built virtual objects through a virtual self-customized representation referred to as an avatar. Users design their own appearance, including age, gender, and species (Wang \& Braman, 2009). Braman, Vincenti, Arboleda and Jinman (2009) remark that users of SL deal with a range of (mostly technical) limitations. However most users agree that the benefits outweigh the limitations, e.g., the general immersive content, 3D social interaction, and realistic visualization. Of particular interest to educators are the "simplified methods for importing external content" for building "rich learning and teaching activities" (Warburton, 2009, pp. 418-419) that support multifaceted social interaction.
}

by, included in, and interacting with an environment that provides a continuous stream of stimuli and experiences"' (p. 227).

When persona role-play and performative learning become part of a complex virtual social community, the potential to further challenge learners and produce a new range of emotional experiences is greatly increased. Salmon (2009) describes it as an experience that "transcends being a 'puppet' to that of extension of self" (p. 533). As Warburton (2009) states, “'a virtual world provides an experience set within a technological environment that gives the user a strong sense of being there" (421). In a study by Warburton (2009), findings suggest that the "immersive nature of the virtual world, crossing physical, social and cultural dimensions, can provide a compelling educational experience, particularly in relation to simulation and role-playing activities"' (p. 419). The experience of immersion within virtual worlds has the ability to provide both students and teachers the tools to "project themselves into the learning space," which are "key elements to successful learning transactions"' (p. 419).

\subsection{Play and learning}

Play represents a significant opportunity to accomplish enhanced learning in virtual worlds. Play is also a useful construct for understanding human-computer interaction ${ }^{3}$ (HCI) relative to behavioral measures of playfulness (Webster et al., 1993). For this reason, researchers must continue to explore the psychological dimensions and related value of what makes gameplay motivating, specifically in a learning context (Oliver \& Carr, 2009).

Csikszentmihalyi and Csikszentmihalyi (1988) notes that play has its own innate motivators, arguing that what makes "play" enjoyable are its built-in rewards due to the excitement of uncertainty, what we might refer to as "having an edge." Hence, an increased level of uncertainty heightens the "edge" experienced in play. This often includes the play elements of demand, challenge, and stress, i.e., a "perceived urgency, importance, and significance associated with the experience" (p. 57). He also states that for people to experience flow in play, the outcomes must be: (1) real, meaningful, and fateful, (2) significant, dependent, and "determined by individual volitional action," and (3) "intrinsically rewarding, occasioned by a merging of action and awareness, [and] an absence of self-consciousness.. ." (p. 52). In sum, Csikszentmihalyi argues that over time,

"the purpose of play shifts from the achievement of immediate enjoyment to the earning of ultimate success, from means to ends. ...In an urgent effort to regain a valued but intangible aspect of life, the disenchanted ones search for flow experience in less than encompassing ways...' (p. 56).

When the level of both challenge and skill is high, a gameplayer not only enjoys the moment, but is "stretching his or her capabilities with the likelihood of learning new skills and increasing selfesteem and personal complexity" (Csikszentmihalyi \& LeFevre, 1989, p. 816). These experiences are translated from game design that directs gamers along a continuum of action in which there is

\footnotetext{
${ }^{3}$ Human-computer interaction is the study of human-centered design, development, and implementation of usable and socially acceptable information technologies. This field of study is grounded in theories and applied techniques to better understand the interaction between people and technology, e.g., computers, mobile devices, and ubiquitous systems. HCI is a multidisciplinary field that includes the cognitive and behavioral sciences (including anthropology and sociology), computing and informatics, and the communication sciences. In particular, it includes the design fields of interface design and interaction design theory and practice in the forming of system representations that better support more intelligible human interpretation and use of technology through reliability, usability, and acceptability empirical research.
} 
greater or lesser degrees of risk and control over the game played. This experience is then juxtaposed to their personal skill levels and ability to mount strategic offensives (Ball, 1972).

Virtual gaming environments that have a particular pedagogical component provide opportunities for educators to motivate learners. Inal and Cagiltay (2007) state that "children's optimal flow experiences have a direct relationship with their motivation" (p. 456). For example, research suggests that gameplay may have a positive impact on children's learning, because it encourages critical thinking (Lim, Nonis, \& Hedberg, 2006). This level of motivation is only maintained, however, when there is the thrill of discovering new knowledge and when adventures are laden with surmountable challenges, creating a balance between skills and difficulty. To increase the potential for enriching and maintaining flow, games should specify challenge levels, provide specific goals, and give appropriate feedback (Dreher, Reiners, \& Dreherb, 2009; Kiili, 2005; Sweetser \& Wyeth, 2005). These directives were substantiated by a study by Inal and Cagiltay (2007), who found that children experienced flow during gameplay when they were " "absorbed" in the game, because they were "only thinking of passing to the next level of the game or achieving the given task at these times," while being "less aware of both themselves and their friends"' (p. 459).

Carr et al. (2010) hold that educators still face a range of issues when working with virtual worlds. They complain that "the research emerging from a digital game studies perspective... is rarely used by educators researching the pedagogic potentials of virtual worlds such as Second Life"' (p. 446). Their research links game-based learning and formal education by framing learning as a social process, i.e., "computer games in learning contexts" (p. 456).

According to Ravenscroft and McAlister (2006), e-learning researchers are beginning to acknowledge the difficulties in engaging and sustaining the motivation of online learners. As a result, some educators are becoming increasingly enthusiastic about the potential of gameplay as a new interactive paradigm that delivers fun, engagement, and enjoyment, while students learn. Dreher et al. (2009) state that like the "individual flow experiences of children, their social flow experiences might be influenced by computer games fostering or encouraging them to interact with each other' (p. 456). In other words, the relationship between virtual gameplay and multiple players can be characterized by a learning experience that is directly affected by a heightened level of enjoyment, i.e., social telepresence resulting from flow.

\section{Enhancing virtual learning through telepresence}

Additionally relevant to virtual learning is the relationship between flow and telepresence (Oliver \& Carr, 2009; Salmon, 2009; Shin, 2006; Warburton, 2009). In particular, beyond the basic qualities of flow, such as enjoyment and intrinsic interest, we need to more thoroughly examine the phenomenon of telepresence, which refers to a compelling feeling of being present in a virtual space. This feeling is sometimes strongly associated with vividness, arousal, focused attention, and interactivity, as well as high degrees of skill and control (Choi \& Kim, 2004; Draper \& Blair, 1996; Finneran \& Zhang, 2003; Novak et al., 2000; Sheridan, 1992; Steuer, 1992).

Contrary to the experience of being present or "being here," telepresence is the experience of "being there" or being in parallel space by means of a specific computer-mediated vehicle. For example, through the use of a communication medium (Steuer, 1992), the environment may be a distant location viewed through a digitally generated virtual world, such as the game World of Warcraft or Final Fantasy XII. In a study on flow, Pace (2004) described the experience of telepresence of one virtual world participant by noting that he felt like he was actually " present in the environment generated by the computer ... [and that he] forgot that he was just looking at pixels on a screen"' (p. 357). In this case, the participant became immersed in a virtual experience that was entirely manufactured through electronic means. What this suggests is that the informant's experience of flow was enhanced with a cognitive sense of depth and of " being there,"' that is, in a 3D environmental simulation somewhere in virtual space.

In the context of flow, telepresence can produce a sense of time distortion and forgetting about one's immediate surroundings. In other words, the "awareness of one's surroundings-disappear from consciousness" (Pace, 2004, p. 358). Steuer (1992) states that the level of vividness in a person's experience of a computer-mediated environment contributes greatly to the level of telepresence that can be experienced. Concurrent with a sense of vividness, responsiveness is a key factor, which is largely dictated by the robustness or speed of the system and the realness of the computer-generated graphics being used to deliver the mediated virtual-world experience. Agah and Tanie (1999) describe technology that can produce a telepresence experience as a system that "provides the user with the feeling of being present in a remote location through the use of images, sounds, and (at times) touch" (p. 107). Telepresence demands focused attention, however. In a computer-mediated environment, "telepresence is an essential factor for enabling the person to remain concentrated on the computer-based task" (Finneran \& Zhang, 2003, p. 484). The users' undivided attention is required to produce flow and to transport their consciousness to a virtual space. Other studies have also produced significant findings that support the relationship between enjoyment and telepresence as variables affecting flow in the context of human-computer interaction (Skadberg \& Kimmel, 2004).

Draper and Blair (1996) concur with the need for a heightened level of attention, stating that telepresence arises from "commitment of attentional resources to the remote task. The more resources a user devotes to the task, the greater the identification of the user with the task and the stronger the sense of telepresence. ... One could hypothesize that telepresence (as it relates to flow) is the perception arising from allocation of attentional resources, while subjective workload is the perception of the allocation itself', (p. 1033). Csikszentmihalyi (1997) argued that the experience of flow and the associated heightened enjoyment occurs more readily when there is a balance between an individual's skill and the difficulty of the task or activity. Most striking is how both flow and telepresence share the characteristic of concentration on task. As Draper and Blair (1996) argue, both demand a level of concentration void of any "distracting stimuli to the point of loss of awareness of self as separate from the task" (p. 1030).

Telepresence becomes a particularly powerful tool for learning when it is paired with a group experience. Whereas telepresence is a mediated experience of spatial presence, social learning presence refers to the sense of being with others during a virtual learning experience. A remarkable phenomenon can be observed when these two interrelated phenomena combine harmoniously in social learning spaces. Telepresence becomes social telepresence when social learning ${ }^{4}$ is sustained by a mediated environment such as a virtual world (Biocca, Harms, \& Burgoon, 2004; Steuer, 1992).

Research in the area of social presence dates back to work done by Short (1974) and others. Edirisingha et al. (2009) hold that

\footnotetext{
${ }^{4}$ To support virtual group participation and communication, an assortment of new media is required, including $3 \mathrm{D}$ graphics and animation, an array of visual constructs, nonverbal-gestural, voice, and textual media (Dreher et al., 2009). The difficulty, however, is that the precise nature of learning and knowledge construction through virtual worlds is still unknown. As Dreher et al. (2009) note, there are still many " "powerful pedagogical utilities of virtual worlds that are not yet fully evolved or utilized. ..' (p. 212).
} 
social presence theory can assist in understanding the "extent to which a medium is able to convey a sense of the participants' being physically present," what Witmer and Singer (1998) define as a "subjective experience of being in one place or environment, even when one is physically situated in another' (p. 225). In either case, challenges to reaching some goal can increase flow, while reducing the "emotional and psychological distance between distance learners" (p. 460). Hence, researchers continue to examine ways whereby distance-learning within a virtual context like SL can "facilitate social presence," "foster socialization," and maximize the experience of flow (Edirisingha et al., 2009; Kehrwald, 2008; Salmon, 2004).

Having an online social telepresence or "virtual awareness" becomes extremely relevant in virtual learning as a facet of flow. Together, social presence and flow provide for a complex mix of theory and practice relative to how one comes to think and feel, discovers new knowledge, acquires trust, interacts with others, and cultivates intrinsic motivation in a virtual learning community (Draper \& Blair, 1996; Faiola \& Voiskounsky, 2007; Schroeder, 2002; Sherry, 2004; Woolfolk, 2006). Educators are beginning to recognize that socialization plays a crucial role in virtual contexts, impacting learners' " "perception of their context of study and learning outcomes"' (p. 459). In such cases, the design of online environments and learning scenarios will have a dramatic impact on socialization and the level of pleasure learners experience in virtual worlds (Salmon, 2004). Hence, the methods that virtual learners employ to discover and share knowledge as a social group will be of great interest to future researchers.

Squire notes that from a "social perspective" there are several ways to understand learning as a social achievement, not just a process of content acquisition or skills development (Squire, 2002). He goes onto argue that despite increased attention on games " as a maturing medium, the pedagogical potential of games and social contexts of gaming have been woefully unexamined." Hence, considering gameplay practices from novel perspectives could shed new light on social presence and related learning outcomes.

\section{Research hypotheses}

\subsection{The Hoffman and Novak conceptual model}

Whether we divide flow into nine components (Csikszentmihalyi, 1990), five components (Hoffman \& Novak, 1996), or three components (Rodriguez-Sanchez \& Schaufeli, 2008), it would not be possible to conduct an intelligible exploration of flow and learning unless the interrelationships among all of these components were clearly delineated. Fortunately, a conceptual model was devised to examine these interrelationships (Hoffman \& Novak, 1996; Novak, Hoffman, \& Yung, 1998). In it, flow is defined as a computer-mediated activity with a seamless sequence of responses, which is enhanced by telepresence.

Hoffman and Novak (1996) showed that "focused attention leads to arousal and telepresence, which both lead to flow" (p. 56). To show the interrelationship of these factors they measured a predictive fit of various theoretical relationship models against responses to web-based questionnaires. Two years later, in a study designed to further fine-tune this conceptual model, Novak et al. (1998) used similar methods to determine that the speed of userinteraction increases the challenge of the interaction and re- sults in more focused attention on the problem by the participant. An increase in the balanced factors of challenge and perceived skill increases the likeliness of the user engaging in play behavior. These findings suggest that an increased focus of attention results in increased play, arousal, and sense of telepresence, which further leads to an increased likelihood of experiencing flow. It is important to note that the same study employed a "comparative fit index" to demonstrate that telepresence, in conjunction with play and arousal, leads to flow in a cognitive model.

At present, flow's facilitation by telepresence is still relatively unexplored. In fact, it is not necessarily true that either condition is present in virtual worlds. Therefore, the study described in this paper examines the correlation between telepresence and flow in more detail after first establishing the presence of each. We believe that these topics are the most complex and in need of the most fundamental research. To determine the potential impact of flow and telepresence on virtual gameplay and learning, basic questions need to be answered about whether participants feel flow in virtual environments and what factors affect the participants' experience of telepresence. An understanding of the correlation between flow and telepresence is also needed to provide insight into their combined influence on virtual gaming and learning.

In summary, flow through telepresence has the potential to increase enjoyment and facilitate greater degrees of motivation for gamers and learners of virtual world communities, while providing additional insight into HCI theory and best practice. Nevertheless, few studies addressing virtual worlds focus specifically on flow and telepresence, and their relationship to gameplay and learning. Hence, to arrive at a better understanding of the impact of flow and telepresence on game-based learning, the authors in this study first determine the degree to which flow and telepresence exist in a 3D virtual world, such as Second Life. Second, they determine the level of correlation between flow and telepresence.

From this vantage point, the authors posit that flow is positively associated with degrees of immersion and telepresence, with direct consequences for virtual game-based learning. Hence, they ask, what are the determining factors influencing flow within a virtual world, what is the relationship between telepresence and flow, and how do these factors and effects impact users during virtual gameplay and learning? Corresponding hypotheses are as follows:

$\mathrm{H}^{1}$ Participants experience flow while using SL.

$\mathrm{H}^{2}$ Participants experience telepresence while using SL.

$\mathrm{H}^{3}$ Flow experience is positively correlated with the experience of telepresence while using SL.

\section{Methodology}

\subsection{Participants}

There are approximately 14 million virtual community users of SL. Site supported statistics show that an average of five hundred thousand residents log-in weekly. Although English is the official language in the majority of the virtual communities, and the majority of users are from the USA, a diverse group of geographic locations and national cultures is represented. Participants for this study were recruited from the English-speaking SL population, in particular from five SL discussion groups, readers of prominent resident blogs dedicated to SL, and public forum listings made available within SL.

A total of 115 SL users participated in the study: 47 males and 68 females ( $41 \%$ and $59 \%$ respectively), most of them (62\%) in their thirties or forties. Only one participant reported having beginner computer skills, 35 (30\%) defined themselves as intermediate computer users, and 79 defined themselves $(68 \%)$ as experts. Similar percentages were reported for Internet skills. Most of the participants had completed undergraduate or post-graduate degrees (86\%). Almost all participants spent more than $20 \mathrm{~h}$ per week using the computer and online. The majority of the participants stated work as the main reason for using the Internet and 31 participants 
(or $27 \%$ of respondents) stated communication as their main motivation of Internet use.

\subsection{Treatment}

Flow researchers have developed two main approaches to their methodology. Besides the "open" interview, the most common method is "experience sampling," which was originated by Csikszentmihalyi and Csikszentmihalyi (1988). This latter method is administered as short questionnaires that participants fill out during an activity. It requires much effort from participants, e.g., carrying a pager or downloading software for entering feedback, or filling out a questionnaire at random times throughout the day. The authors preferred to use an online questionnaire to gather the responses, choosing a multiple choice survey instead of the open interview or experience sampling methods. Based on this method the authors were able to collect more data in a shorter period of time, with the primary goal of reaching as many respondents as possible.

The primary online questionnaire was composed of 23 multiple-choice questions based on information gathered from formative research on flow, gaming, and virtual reality, as well as several exploratory questions the authors believed would provide specific insights on the relationship between online virtual communities, flow, and telepresence (McKenna \& Lee, 1995; Novak and Hoffman, 1997; Voiskounsky, Mitina, \& Avetisova, 2005, 2006). The 23 questions in the primary section were further separated into two sections; the first section was related to flow experience (13 questions), and the second was related to telepresence patterns (10 questions), each focusing on the participants' experience in a virtual community, i.e., in SL. The second section was composed of four parts related to the participants' level of computer experience, e.g., general online experience, general computer experience, and demographic information. Participants had to evaluate their experiences by rating each flow and telepresence statement on a scale of one to five. Several negative statements were included in the questionnaire to balance mostly positive statements. The questionnaire was delivered using the online service Survey Monkey.

\subsection{Data analysis}

$\mathrm{H}^{1}$ and $\mathrm{H}^{2}$ were analyzed using one-sample t-tests, being intended as prerequisites for testing $\mathrm{H}^{3}$. That is, without evidence that respondents actually experienced flow and telepresence, testing for any correlation between the two would be impossible. Further analysis was performed to see whether any of the data gathered on computer usage and demographics played a role in the experience of flow or telepresence.

$\mathrm{H}^{3}$ was analyzed using factor analysis to study the relationships between flow and telepresence, as well as the subcomponents contained within each of those variables. As this data was collected with a priori hypotheses about the relationships between the variables, factor analysis provides the means to measure the shared variances between items and reveal latent variables underlying this covariance. While principal components analysis (PCA) is often used in similar research, it disregards any such underlying variables and can overestimate the amount of variance accounted for by each factor (Gorsuch, 1990). Though factor analysis and PCA may converge upon the same solution with large numbers of items and fairly high communalities between variables, this study does not meet those criteria.

Factors were extracted using the maximum likelihood method due to the overall normality of the data. The method to identify the number of factors for each analysis was an inspection of the scree plot, confirmed with parallel analysis (Hayton, Allen, \&
Scarpello, 2004). This method is considered much more accurate than the frequently used Kaiser criterion (selecting all factors with eigenvalues greater than 1), which generally overestimates the appropriate number of factors (Velicer \& Jackson, 1990). As some correlation between factors was expected, an oblique rotation (direct oblimin) was used. A minimum loading of .40 on only one factor was required to assign an item to a factor. Analysis was performed using SPSS 17.

\section{Results}

\subsection{Hypotheses one and two}

The mean responses for both factors (flow and telepresence) were significantly higher than the midpoint of the scale $\left(l_{0}=3.00\right)$, thus satisfying both of these prerequisites for the purposes of this analysis (flow: $\mathrm{t}(114)=13.77, \mathrm{p}<.001$; telepresence: $\mathrm{t}(114)=9.73, \mathrm{p}<.001)$. The mean response for flow was 3.82 , $\mathrm{SD}=0.64$; the mean response for telepresence was $3.65, \mathrm{SD}=0.72$.

After inverting the two reverse-coded items in the flow scale, reliability analysis was performed on both scales. Both the flow and telepresence scales had high reliabilities, Cronbach's $\mathrm{a}=.88$ (flow) and .87 (telepresence), with average inter-item correlations of .40 and .47 , respectively. No items, if removed, would have resulted in any substantial increase in either scale's reliability. The after squaring both scales for a normal distribution, flow and telepresence scales were found to be positively correlated, $\mathrm{r}=.56$, $\mathrm{p}<.001$.

Further analysis was performed to see whether any of the data gathered on computer usage and demographics played a role in the experience of flow or telepresence. Gender showed no impact on either scale $(p>.05)$. However, the degree of flow experienced increased by age group, with the oldest respondents (56-65 years old) experiencing the most flow $(\mathrm{M}=4.16, \mathrm{SE}=0.15)$, and the youngest respondents (18-25 years old) experiencing the least flow $(\mathrm{M}=3.47, \mathrm{SE}=0.15), \mathrm{F}(4,110)=3.44, \mathrm{p}<.05$, difference significant at $\mathrm{a}=.05$ per Tukey's HSD test.

\subsection{Hypothesis three}

The first factor analysis examined the entire data set across all 23 questions to determine the relationships between the two main questionnaire topics, flow and telepresence. The data was screened for univariate outliers, finding none. Reasonable factorability was indicated by all items correlating at least .3 with two or more other items, and the diagonals of the anti-image correlation matrix for all items were .67 or greater, confirming inclusion of all 23 items in the factor analysis. The Kaiser-Meyer-Olkin (KMO) measure of sampling adequacy was strong at .84 , and Bartlett's test of sphericity was significant, $\mathrm{v}^{2}(253)=1357.67, \mathrm{p}<.001$.

The scree plot and subsequent parallel analysis indicated a twofactor solution, as anticipated. Table 1 shows the factor loadings after rotation. The composition of factors confirms the construction of the survey overall, with the first factor, Flow, explaining $37.04 \%$ of the variance, and the second factor, Telepresence, explaining $8.93 \%$ of the variance. However, there were two exceptions. Question 13 ("I can easily control objects while in Second Life"), though intended as a flow item, loaded on the telepresence factor. Question 15 ("I feel aware of my surroundings in Second Life"), was intended as a telepresence item but loaded on the flow factor. Four items were dropped for not meeting the minimum loading criteria: "I feel confident while in Second Life", (flow), "When I'm in Second Life it feels "effortless", (flow), "I think of being in Second Life as an extension of the "Real World", (telepresence), and "I experience 
Table 1

Mean responses, factor loadings and communalities based on maximum likelihood analysis with direct oblimin rotation for the 23 flow and telepresence items.

\begin{tabular}{|c|c|c|c|c|c|}
\hline & & Mean response & Flow & Telepresence & Communality \\
\hline 1 & I often feel anxious while in Second Life & $1.9^{\mathrm{a}}$ & -.50 & .02 & .24 \\
\hline 2 & I often feel bored while in Second Life & $2.1^{\mathrm{a}}$ & -.62 & .07 & .34 \\
\hline 3 & I often feel in control while in Second Life & 3.7 & .50 & .01 & .26 \\
\hline 4 & I feel completely involved in Second Life & 3.7 & .80 & .07 & .70 \\
\hline 5 & I feel focused while in Second Life & 3.7 & .72 & .04 & .54 \\
\hline 6 & I feel comfortably challenged while in Second Life & 3.5 & .77 & -.12 & .50 \\
\hline 7 & I lose track of time while in Second Life & 3.8 & .51 & .08 & .32 \\
\hline 8 & I feel at ease while in Second Life & 4.0 & .59 & .10 & .43 \\
\hline 9 & Time really flies when I'm in Second Life & 3.9 & .45 & .17 & .32 \\
\hline 10 & I feel confident while in Second Life & 3.8 & .30 & .36 & .34 \\
\hline 11 & I feel engaged while I'm in Second Life & 3.8 & .79 & -.07 & .57 \\
\hline 12 & When I'm in Second Life it feels "effortless", & 3.3 & .37 & .26 & .31 \\
\hline 13 & I can easily control objects while in Second Life & 3.8 & -.14 & .70 & .39 \\
\hline 14 & I think of being in Second Life as an extension of the "Real World", & 3.3 & .09 & .31 & .13 \\
\hline 15 & I feel aware of my surroundings in Second Life & 4.1 & .52 & .18 & .41 \\
\hline 16 & My interactions with the in Second Life environment seem very natural & 3.7 & -.12 & .96 & .79 \\
\hline 17 & I feel like all of my senses are engaged while in Second Life & 3.0 & .13 & .55 & .40 \\
\hline 18 & Moving around in the Second Life environment feels very natural & 3.7 & -.02 & .86 & .72 \\
\hline 19 & I feel like I'm actually moving through the virtual world in Second Life & 3.5 & .08 & .63 & .47 \\
\hline 20 & I can anticipate the responses to my actions in Second Life (I kick a ball, it moves) & 3.6 & -.02 & .49 & .23 \\
\hline 21 & I can examine objects from multiple viewpoints in Second Life & 4.3 & .23 & .46 & .39 \\
\hline 22 & I experience little delay from my actions to the expected outcomes & 3.4 & .14 & .28 & .14 \\
\hline 23 & I feel like I am really "there" in the virtual world, i.e., in Second Life & 3.7 & .31 & .56 & .61 \\
\hline
\end{tabular}

Notes: Items 1-13 were originally intended to elicit feelings about Flow. Items 14-23 were intended to elicit feelings about Telepresence. Factor loadings >.40 are indicated in bold.

a Indicates reverse-coded items.

little delay from my actions to the expected outcomes" (telepresence).

Each of these two scales was then analyzed to determine the existence of sub-factors among the flow and telepresence items. However, factor analysis of each scale revealed only one-factor solutions. Therefore, no additional subscales of either flow or telepresence were identified.

\section{Discussion}

Traditional cognitive approaches to research in HCI (such as SOAR and ACT- $\mathrm{R}^{5}$ ) have tended to underestimate emotion and pleasure as factors that can have a dramatic influence on user experience. As Norman (2004) asserts, affect is linked to attitudes, expectations, and motivations, and produces a level of emotional response that plays a significant role in user cognition. These emotional states can be complex and can influence and even mediate aspects of user interaction, shaping one's virtual world experience.

Applying HCI design theory to the development of computermediated environments, such as virtual worlds, can facilitate the experience of flow and has the potential to increase users' pleasure. For example, Ghani and Deshpande (1994) state that flow and high levels of enjoyment are correlated with higher online experimentation and exploration. These positive experiences of online users have wide implications for serious gaming researchers and educators.

The fact that effective HCI design can lead to higher degrees of flow is important in that it indicates that Csikszentmihalyi's model is suitable for examining the quality of users' experiences with

\footnotetext{
5 Soar is a computational theory developed by Newell (1990) for modeling a wide variety of human cognitive activities from syllogistic reasoning (Polk \& Newell, 1995) to aircraft simulations (Jones et al., 1999). As Byrne notes, "Soar casts all cognitive activity as occurring in a problem space, which consists of a number of states.. transformed through the applications of operators"' (p. 100). ACT-R (Adaptive Control of Thought-Rational) is a theoretical model that can be applied to HCI related to cognitive architecture related to problem solving, learning and memory (Byrne, 2001).
}

technology, in particular online experiences within virtual worlds. This is because the requirements for a flow-inducing virtual experience (such as within SL) may be exactly the same as the demands for a user interface that has a high degree of usability. Finneran and Zhang (2003) came to the same conclusion when they identified that the high-level conceptualization of Csikszentmihalyi's flow model still needs to be challenged as it applies to a range of information technology environments. Moreover, Finneran and Zhang argue that "in order for MIS/HCI researchers to progress further in understanding the antecedents of flow, we need to re-examine the over-arching framework of the original flow work [of Csikszentmihalyi]', (p. 493).

Our findings support recent research (Faiola \& Voiskounsky, 2007; Finneran \& Zhang, 2005; Pilke, 2004; Rodriguez-Sanchez \& Schaufeli, 2008; Sherry, 2004; Skadberg \& Kimmel, 2004) that suggest that flow experience is a significant cognitive state in online activities. In particular, our findings for $\mathrm{H}^{1}$ and $\mathrm{H}^{2}$ support our position that both flow and telepresence are experienced in measurable ways in virtual space, and that flow can be positively associated with degrees of immersion and telepresence in a $3 \mathrm{D}$ virtual world such as SL. More importantly, we propose that considerable evidence supports $\mathrm{H}^{3}$, which states that flow can be correlated with telepresence. These findings also engender hope that virtual learners who experience flow may learn more about the educational subject matter provided online, leading to changes of attitude and behavior, including taking positive actions (Skadberg \& Kimmel, 2004).

Hence, based on the correlations between several important indicators of flow, the authors can conclude that there are strong connections between flow and telepresence in SL, and that the ability to interact with the virtual environment in a natural way can enhance a feeling of being present in a virtual world. At the same time, these correlations not only improve the current understanding of the virtual reality experience, they also provide partial support for models that seek to understand these interrelationships (Csikszentmihalyi, 1990; Hoffman \& Novak, 1996; Novak et al., 1998). 


\section{Conclusion}

This paper represents an attempt to disentangle the complex relationship between flow and telepresence in a virtual world. This research also attempted to advance the discussion of the relationship between flow and telepresence by presenting some observations of participant responses to questions related to the experience of virtual worlds. The authors argue that substantiating the presence of flow and telepresence in virtual worlds is not merely a matter of observation. Rather, that virtual world users not only have such experiences but also lose their sense and connection with real-time. In particular, gameplayers often feel totally immersed in the interactivity of a game, losing their sense of time, while feeling a heightened sense of pleasure, or what has been considered the gamers' optimal experience. Hence, the authors conclude that for these observed phenomena to be productively harnessed for use in education, they must be more rigorously understood. For this reason, the authors asked, do users experience flow and telepresence in a virtual world, and what is the correlation between the two?

If we hope to leverage the power of flow to drive advances in commerce and education, it will be necessary to gain a new understanding of the experiences of users required to support virtual learning. Fortunately, this is an exercise that seems destined to bring its own rewards. Recent trends in research suggest that "flow theory" "provides new insights into field of HCI. However, flow occurs under a limited set of conditions. For example, users experience flow only if their movement through a virtual space feels seamless, while at the same time their skills match available challenges. Because the study of flow can clarify the features that contribute to an optimal experience, it is a more holistic metric for understanding HCI than traditional usability and time-on-task studies. User experiences of flow online can be affected by a number of factors, such as high levels of skill, control, challenge, arousal, and focused attention. Therefore, the study of flow in new environments, such as virtual worlds, has the potential to yield effective new tools for the design of such online spaces.

Moreover, the rich variety of interactions that take place in virtual gaming and learning communities may also provide a unique opportunity to study the effect of flow, providing additional insight into HCI theory and best practice. Hence, an understanding of the mechanisms underlying the enjoyment of virtual experiences will facilitate effective virtual world design with outcomes that directly impact user pleasure.

The final consideration in all this is the implications that these findings have for the field of distance education and emerging technologies that support virtual learning spaces. The fact that we are beginning to have the first rough approximations of cause and effect in the motivation of online learning is very significant. We believe this paper outlines several very important and useful first steps in understanding the complex interrelationships between flow and telepresence as users engage in online virtual learning and gameplay. For the future, we hope gathering additional evidence will allow us to better describe a person's experience while moving within a virtual world. We also hope that such research will be of value to virtual world developers and educators, helping them to create worlds with features to significantly enhance the user's immersive experience.

\section{Acknowledgments}

Much gratitude goes to Kristina J. Ledford (MS HCI Graduate from the Indiana University School of Informatics) for her work in completing and managing the online survey and data collection process.

\section{References}

Agah, A., \& Tanie, K. (1999). Multimedia human-computer interaction for presence and exploration in a telemuseum. Presence: Teleoperators and Virtual Environments, 8(1), 104-111.

Ball, D. (1972). What the action is: A cross-cultural approach. Journal for the Theory of Social Behavior, 2, 121-143.

Biocca, F., Harms, C. J. K., \& Burgoon (2004). Toward a more robust theory and measure of social presence. Review and suggested criteria. Presence, 12(5), 456480.

Braman, J., Vincenti, G., Arboleda Diaz, A. M., \& Jinman, A. (2009). Learning Computer Science Fundamentals through Virtual Environments. Proceedings of the 3rd International Conference on Online Communities and Social Computing: Held as Part of HCI International, 2009, 423-431.

Brandt, R. (1995). Punished by rewards? A conversation with Alfie Kohn. Educational Leadership, 53(1), 13-16.

Byrne, M. D. (2001). ACT-R/PM and menu selection: Applying a cognitive architecture to HCI. International Journal of Human-Computer Studies, 55, 41-84.

Carr, D., Oliver, M., Burn, A. (2010). Learning, teaching and ambiguity in virtual worlds. In: Peachey, A., Gillen, J., Livingstone, D., Smith-Robbins, S. (Eds.), Researching learning in virtual worlds. New York: Springer.

Carroll, J. M., \& Thomas, J. C. (1988). Fun. SIGCHI Bulletin, 19(3), 21-24.

Chan, T. S., \& Ahern, T. C. (1999). Targeting motivation: Adapting flow theory to instructional design. Journal of Educational Computing Research, 21(2), 151-163.

Chance, P. (1992). The rewards of learning. Phi Delta Kappan, 73, 200-207.

Choi, D., \& Kim, J. (2004). Why people continue to play online games: In search of critical design factors to increase customer loyalty to online contents. CyberPsychology \& Behavior, 7(1), 11-24.

Csikszentmihalyi, M. (1975). Beyond boredom and anxiety. San Francisco: JosseyBass.

Csikszentmihalyi, M. (1990). Flow: The psychology of optimal experience. New York: Harper \& Row.

Csikszentmihalyi, M. (1997). Finding flow: The psychology of engagement with everyday life. New York: HarperCollins.

Csikszentmihalyi, M., \& Csikszentmihalyi, S. (1988). Optimal experiences: Psychological studies of flow in consciousness. New York: Cambridge University Press.

Csikszentmihalyi, M., \& LeFevre, J. (1989). Optimal experience in work and leisure. The Journal of Personality and Social Psychology, 56(5), 815-822.

Davis, F. D. (1989). Perceived usefulness, perceived ease of use, and user acceptance of information technology. MIS Quarterly, 13(3), 319-340.

Draper, J. V, \& Blair, L. M (1996). Workload, flow, and telepresence during teleoperation. In Proceedings of the 1996 IEEE international conference on robotics and automation (pp. 1030-1035). Minneapolis, MN: IEEE Robotics and Automation Society.

Dreher, C., Reiners, T., \& Dreherb, N. (2009). Virtual worlds as a context suited for information systems education: Discussion of pedagogical experience and curriculum design with reference to Second Life. Journal of Information Systems Education, 20(2), 211-224.

Edirisingha, P., Nie, M., Pluciennik, M., \& Young, R. (2009). Socialisation for learning at a distance in a 3-D multi-user virtual environment. British Journal of Educational Technology, 40(3), 458-479.

Faiola, A., \& Smyslova, O. (2009). Flow experience and telepresence in second life: Correlating pleasure, immersion, and interaction in virtual communities. In Salvendy, G., Jacko, J. (Eds.), Proceedings of the 13th international conference on human-computer interaction. San Diego, CA. (Mahwah, NJ: Lawrence Erlbaum).

Faiola, A., \& Voiskounsky, A. E (2007). Flow experience of MUD players: Investigating multi-user dimension gamers from the USA. In G. Salvendy \& J. Jacko (Eds.), Proceedings of the 12th international conference on human-computer interaction (pp. 324-333). Beijing: China, Mahwah, NJ: Lawrence Erlbaum.

Finneran, C. M., \& Zhang, P. (2003). A person-artefact-task (PAT) model of flow antecedents in computer-mediated environments. International Journal of Human-Computer Studies, 59(1), 475-496.

Finneran, C. M., \& Zhang, P. (2005). Flow in computer-mediated environments: Promises and challenges. Communications of the Association for Information Systems, 15, 82-101.

Ghani, J. A., \& Deshpande, S. P. (1994). Task characteristics and the experience of optimal flow in human-computer interaction. The Journal of Psychology, 128(4), 381-391.

Ghani, J. A., Supnick, R., \& Rooney, P. (1991). The experience of flow in computermediated and in face-to-face groups, In DeGross, J., Benbasat, I., DeSanctis, G., Beath, C. M. (Eds.), Proceedings of the 12th international conference on information systems (pp. 16-18) New York, NY.

Gorsuch, R. L. (1990). Common factor-analysis versus component analysis: Some well and little known facts. Multivariate Behavioral Research, 25(1), 33-39.

Hayton, J. C., Allen, D. G., \& Scarpello, V. (2004). Factor retention decisions in exploratory factor analysis: A tutorial on parallel analysis. Organizational Research Methods, 7(2), 191-205.

Hoffman, D. L., \& Novak, T. P. (1996). Marketing in hypermedia computer-mediated environments: Conceptual foundations. Journal of Marketing, 60(2), 50-68.

Inal, Y., \& Cagiltay, K. (2007). Flow experiences of children in an interactive social game environment. British Journal of Educational Technology, 38(3), 455-464.

Jones, R. M., Laird, J. E., Nielsen, P. E., Coulter, K. J., Kenny, P., \& Koss, F. V. (1999). Automated intelligent pilots for combat might simulation. AI Magazine, 20(1), $27-41$. 
Katz, J. A. (1987). Playing at innovation in the computer revolution. In M. Frese, E. Ulich, \& W. Dzida (Eds.), Psychological issues of human computer interaction in the work place (pp. 97-112). Amsterdam: North-Holland.

Kehrwald, B. (2008). Understanding social presence in text-based online learning environments. Distance Education, 29(1), 89-106.

Kiili, K. (2005). Digital game-based learning: Toward an experiential gaming model. Internet and Higher Education, 8, 13-24.

Lim, C. P., Nonis, D., \& Hedberg, J. (2006). Gaming in a 3D multiuser virtual environment: Engaging students in science lessons. British Journal of Educational Technology, 37(2), 211-231.

Lutz, R. J., \& Guiry, M. (1994). Intense consumption experiences: Peaks, performances, and flow. In Paper presented at the Winter Marketing Educators Conference. St. Petersburg, FL.

Manyika, J. M., Roberts, R. P., \& Sprague, K. L. (1965). Eight business technology trends to watch. McKinsey Quarterly 12, 5.Maslow, A. (1965). Humanistic science and transcendent experience. Journal of Humanistic Psychology, 5(2), 219-227.

McKenna, K., \& Lee, S. (1995). A love affair with MUDs: Flow and social interaction in multi-user dungeons. <http://www.fragment.nl/mirror/various/McKenna_et_al .nd.A love affair with muds.html $>$ Retrieved 10.03.09.

Moneta, G. B., \& Csikszentmihalyi, M. (1996). The effect of perceived challenges and skills on the quality of subjective experience. Journal of Personality, 64, 266-310.

Newell, A. (1990). Unified theories of cognition. Cambridge, MA: Harvard University Press.

Norman, D. (2004). Emotional design: Why we love (or hate) everyday things. New York: Basic Books.

Novak, T. P., Hoffman, D. L., \& Yung, Y. F. (1998). Modeling the structure of the flow experience among web users. In INFORMS Marketing Sci. Internet Mini-Conf.. MIT

Novak, P. T., \& Hoffman, L. D. (1997). Measuring the flow experience among web users. Palo Alto, CA: Paper presented at Interval Research Corporation.

Novak, T. P., Hoffman, D. L., \& Yung, Y. F. (2000). Measuring the customer experience in online environments: A structural modeling approach. Marketing Science, 19(1), 34-53.

Oliver, M., \& Carr, D. (2009). Learning in virtual worlds: Using communities of practice to explain how people learn from play. British Journal of Educational Technology, 40(3), 444-457.

Pace, S. (2004). A grounded theory of the flow experiences of web users. International Journal of Human-Computer Studies, 60(3), 327-363.

Pilke, E. M. (2004). Flow experiences in information technology use. International Journal of Human-Computer Studies, 61(3), 347-357.

Polk, T. A., \& Newell, A. (1995). Deduction as verbal reasoning. Psychological Review, 102(3), 533-566.

Privette, G., \& Bundrick, C. M. (1987). Measurement of experience. Construct and content validity of the Experience Questionnaire. Perceptual and Motor Skills, 65, $315-332$

Ravenscroft, A., \& McAlister, S. (2006). Digital games and learning in cyberspace. A dialogue approach. E-Learning Journal, Special issue on Ideas in Cyberspace 2005 Symposium, 3(1), 38-51.

Reid, D. (2004). The influence of virtual reality on playfulness in children with cerebral palsy: A pilot study. Occupational Therapy International, 11(3), 131-144.

Rodriguez-Sanchez, A. M., \& Schaufeli, W. B. (2008). Flow experience among information and communication technology user. Psychological Reports, 102, $29-39$

Salmon, G. (2004). E-moderating: The key to teaching and learning online (2nd ed.) London: Routledge Falmer.

Salmon, G. (2009). The future for (second) life and learning. British Journal of Educational Technology, 40(3), 526-538.
Savin-Baden, M. (2008). From cognitive capability to social reform: Shifting perceptions of learning in immersive virtual worlds. The Association for Learning Technology Journal, 16(3), 151-161.

Schroeder, R. (2002). Social interaction in virtual environments: Key issues, common themes, and a framework for research. In R. Schroeder (Ed.), The social life of avatars. Presence and interaction in shared virtual environments (pp. 1-18). New York: Springer.

Sheridan, T. B. (1992). Musing on telepresence and virtual presence. Presence, 1(1), $120-125$.

Sherry, J. L. (2004). Flow and media enjoyment. Communication Theory, 14(4), $328-347$.

Shin, N. (2006). Online learners' flow experience. An empirical study. British Journal of Educational Technology, 37(5), 705-720.

Short, J. A. (1974). Effects of medium of communication on experimental negotiation. Human Relations, 27(3), 325-334

Skadberg, Y. X., \& Kimmel, J. R. (2004). Visitors' flow experience while browsing a web site: Its measurement, contributing factors and consequences. Computers in Human Behavior, 20(3), 403-422.

Somekh, B. (2003). Children exploring a fun Website: Sites of learning and roles of being. In J. Wright, A. McDougall, J. Murnane, \& Lowe, J. (Eds.), Proceedings of young children and learning technologies, international federation for information processing working group open conference (pp. 89-93) Melbourne, Australia.

Spence, J. (2008). Virtual worlds research: Consumer behavior in virtual worlds Journal of Virtual Worlds Research, 1(2). <http://journals.tdl.org/jvwr/article/ view/360/272> Retrieved 22.11.09.

Squire, K. (2002). Cultural framing of computer video games. Game Studies, 2(1). $<$ http://www.gamestudies.org/0102/squire/> Retrieved 15.12.09.

Steuer, J. (1992). Defining virtual reality: Dimensions determining telepresence. Journal of Communication, 42(4), 73-93.

Sweetser, P., \& Wyeth, P. (2005). GameFlow: A model for evaluating player enjoyment in games. Computers in Entertainment, 3(3), 1-24.

Trevino, L. K., \& Webster, J. (1992). Flow in computer-mediated communication. Communication Research, 19, 539-573.

Velicer, W. F., \& Jackson, D. N. (1990). Component analysis versus common factoranalysis: Some further observations. Multivariate Behavioral Research, 25(1), 97114.

Voiskounsky, A. E., Mitina, O. V., \& Avetisova, A. A. (2004). Playing online games: Flow experience. Psychology Journal, 2(3), 259-281.

Voiskounsky, A. E., Mitina, O. V., \& Avetisova, A. A. (2005). Communicative patterns and flow experience of MUD players. International Journal of Advanced Media and Communication, 1(1), 5-25.

Voiskounsky, A. E., Mitina, O. V., \& Avetisova, A. A. (2006). Flow experience and interaction: Investigation of Francophone online gamers. In F. Sudweeds, H. Hrachovec, \& C. Ess (Eds.), Proceedings of cultural attitudes towards communication and technology (pp. 385-398). Estonia: Tartu.

Wang, Y., \& Braman, J. (2009). Extending the classroom through second life. Journal of Information Systems Education, 20, ) 235-247.

Warburton, S. (2009). Second Life in higher education: Assessing the potential for and the barriers to deploying virtual worlds in learning and teaching. British Journal of Educational Technology, 40(3), 414-426.

Webster, J., Trevino, L. K., \& Ryan, L. (1993). The dimensionality and correlates of flow in human-computer interactions. Computers in Human Behavior, 9(4), 411426.

Witmer, B. G., \& Singer, M. J. (1998). Measuring presence in virtual environments: A presence questionnaire. Presence, 7(3), 225-240.

Woolfolk, A. E. (2006). Educational psychology (10th ed.). Pearson, NSW, Australia: Sydney. 